
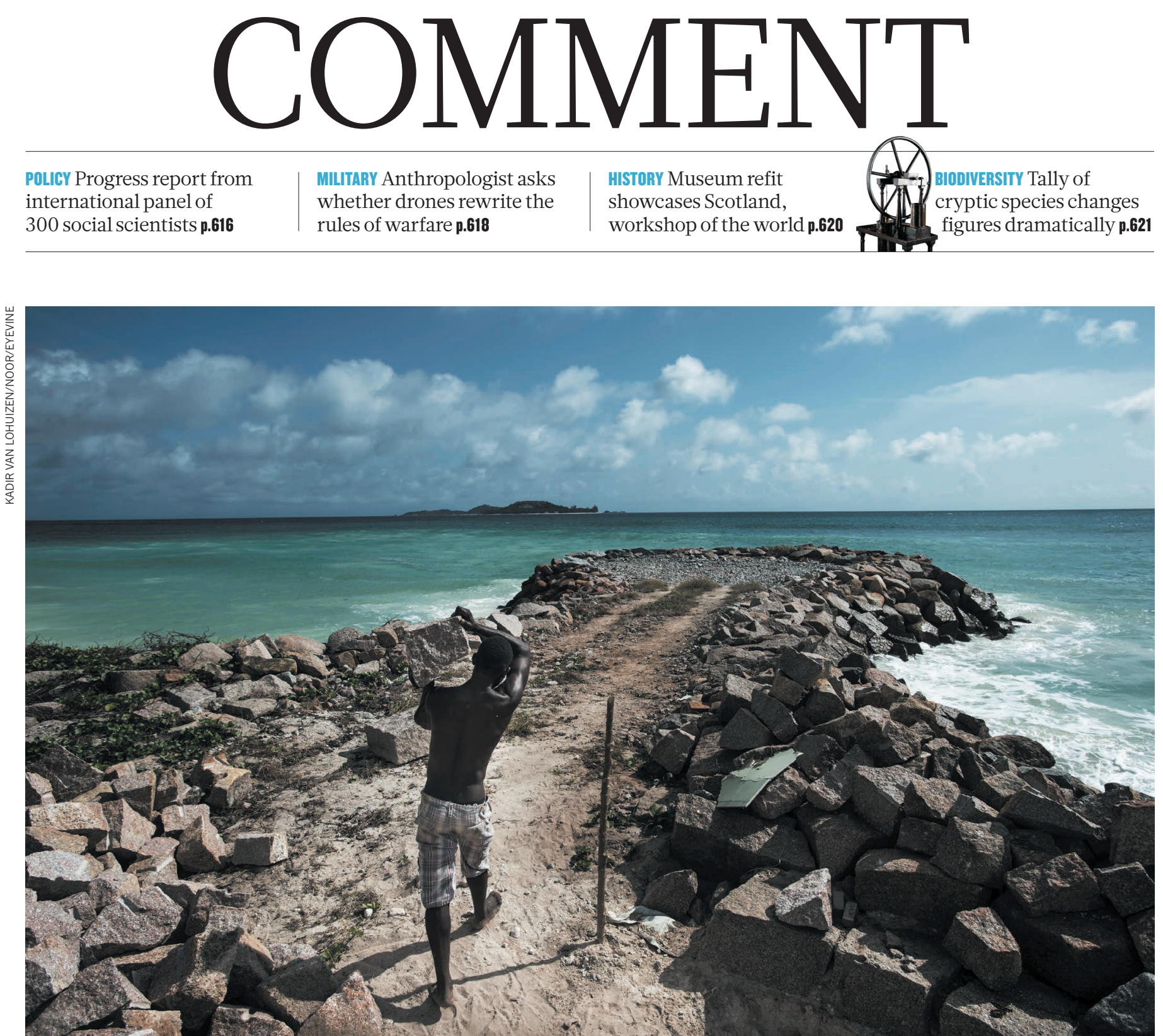

PoLICY Progress report from international panel of 300 social scientists p.616 whether drones rewrite the rules of warfare $\mathbf{p . 6 1 8}$ showcases Scotland, workshop of the world $\mathbf{p . 6 2 0}$

An islander adds to coastal protection at Anse Kerlan beach in the Seychelles.

\title{
Make climate-change assessments more relevant
}

Stéphane Hallegatte, Katharine J. Mach and colleagues urge researchers to gear their studies, and the way they present their results, to the needs of policymakers.

\section{$\mathrm{W}$}

ith the ink just dry on the Paris climate agreement, policymakers want to know how they can act most effectively. Ambition is high: the longterm goal is to keep the average warming of the planet to well below $2{ }^{\circ} \mathrm{C}$, and even to $1.5^{\circ} \mathrm{C}$. Governments, corporations and communities have many options for minimizing dangerous climate change, and must choose between conflicting priorities and objectives. For example, how should governments decarbonize energy while increasing access to it without resorting to fossil fuels?

No single approach will work for all. The risks and impacts of climate change differ by place and time. Local values and contexts matter. Small islands are vulnerable to sea-level rise, for example, and fossil-fuel exporters will lose profits from the transition to low-carbon energy. We must consider value judgements, such as the relative importance of economic damage versus biodiversity loss, as well as inequality and fairness.

And the relevant climate and social $>$ 


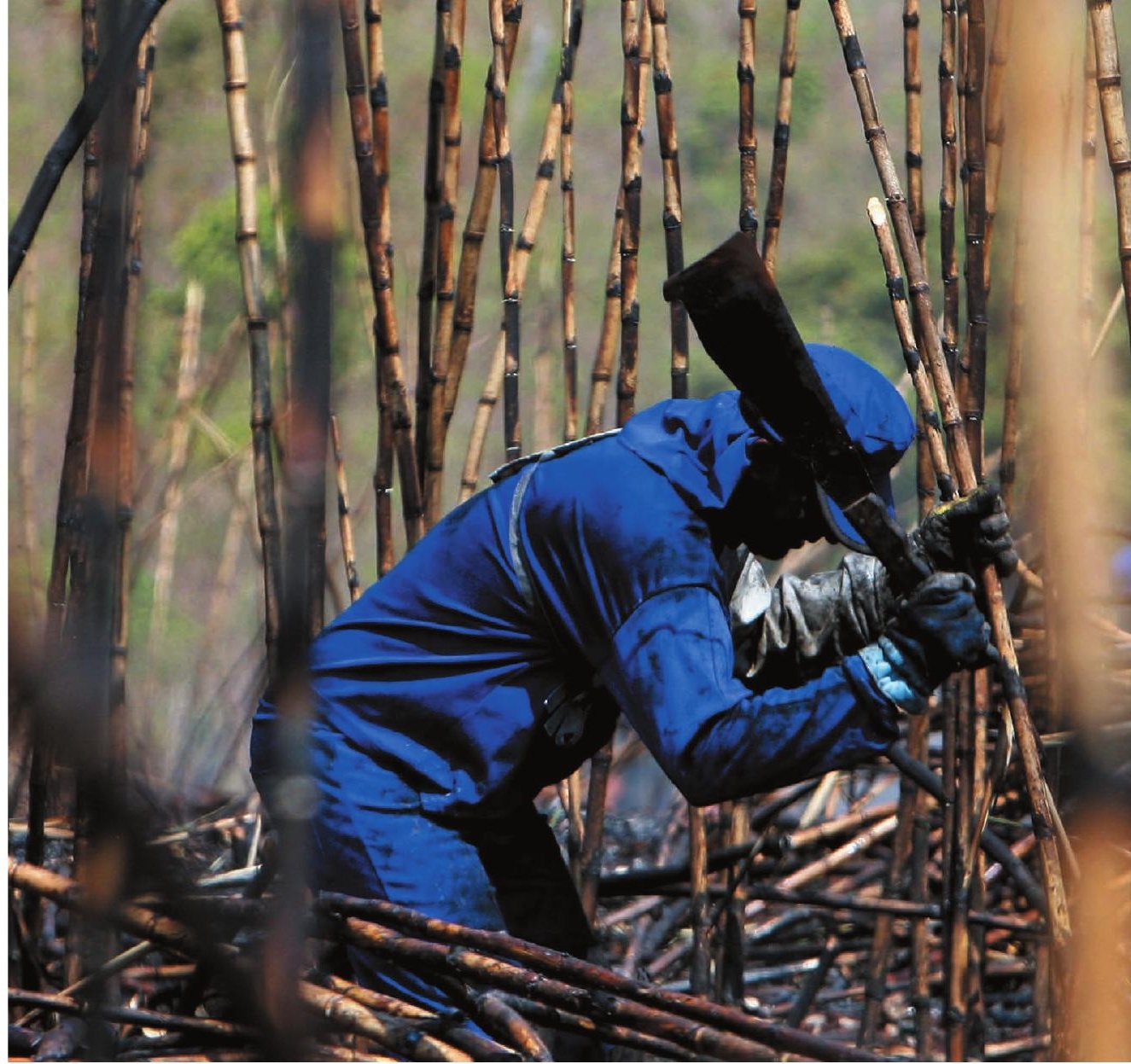

Sugarcane production is rising in Brazil to meet demand for ethanol for biofuel.

evidence and expert judgements across disciplines.

Research and assessments must be designed to solicit and answer questions crucial to decision-making. For example, how do risks and requirements compare for a climate goal at $1.5^{\circ} \mathrm{C}, 2^{\circ} \mathrm{C}$ or more? How can we avoid locking in to carbon-intensive development pathways and keep open options for rapid decarbonization? How can the effectiveness of adaptation actions be ensured? And how can emissions be reduced without slowing the pace of poverty reduction?

at specific warm reporting of broad, qualitative levels of risk - for example, 'undetectable' to 'very high', as judged by experts. But comparison across risks was difficult.

Climate scientists need to close these gaps by scrutinizing the feedbacks between development pathways, climate change and its impacts and risks, and policies and responses. The community has created socio-economic scenarios that are better able to combine climate-policy consequences and climate-change impacts in certain areas such as how poverty reduction reduces vulnerability to extreme events - and to investigate their interplay with development trends ranging from population to land-use trajectories ${ }^{2}$. But covering many climatic and societal futures, globally to locally, is a monumental task. Projects that compare assumptions and results between different models are a start, but need to include more
Explore multiple dimensions. Risks from a changing climate and responses to it vary dramatically from place to place, through time and with different levels of adaptation and mitigation. Projections of increases in sea level for different emissions scenarios, for example, range from tens of centimetres to more than 10 metres over centuries to millennia ${ }^{3}$. Small islands might quickly face inundation whereas large countries would have more time to adapt. Past assessments focused on characterizing a few alternative futures (such as continued high emissions versus ambitious mitigation) rather than weighing up the risks and benefits of limiting warming across a ladder of possible targets: $1.5^{\circ} \mathrm{C}, 2^{\circ} \mathrm{C}, 2.5^{\circ} \mathrm{C}$ or higher.

A broader census of differences through space and time would strengthen the information foundation for policymaking.
Decision-makers with different goals could select portfolios of responses, for example, based on risks to all, risks to the most vulnerable, risks of economic damages, risks of irreversible changes or a combination.

The distribution of losers and winners regarding policies and impacts as well as people and places - needs to be studied. For example, the destruction of coral reefs affects fishing communities and may add to stresses, especially in places with weak governance. In some high-latitude areas, by contrast, a warming climate will bolster agricultural yields. Building sea walls could reduce coastal flood risks but threaten ecosystems, historical heritage and landscape beauty. Risks and opportunities from investments in mitigation options need to be evaluated. For example, expanding biomass energy may reduce (or reverse) emissions but could also threaten food production and biodiversity. Renewable energy reduces emissions and provides electricity more cheaply than that from fossil fuels in many remote locations, where some of the poorest people live.

More research is needed on regional challenges and opportunities that go beyond the use of a single metric - global mean warming - as a proxy for climate change and its impacts ${ }^{4}$. For example, ocean acidification and sea-level rise are not linearly related to peak temperature, and the risks that they create require more detailed investigation. And reducing emissions of short-lived climate 


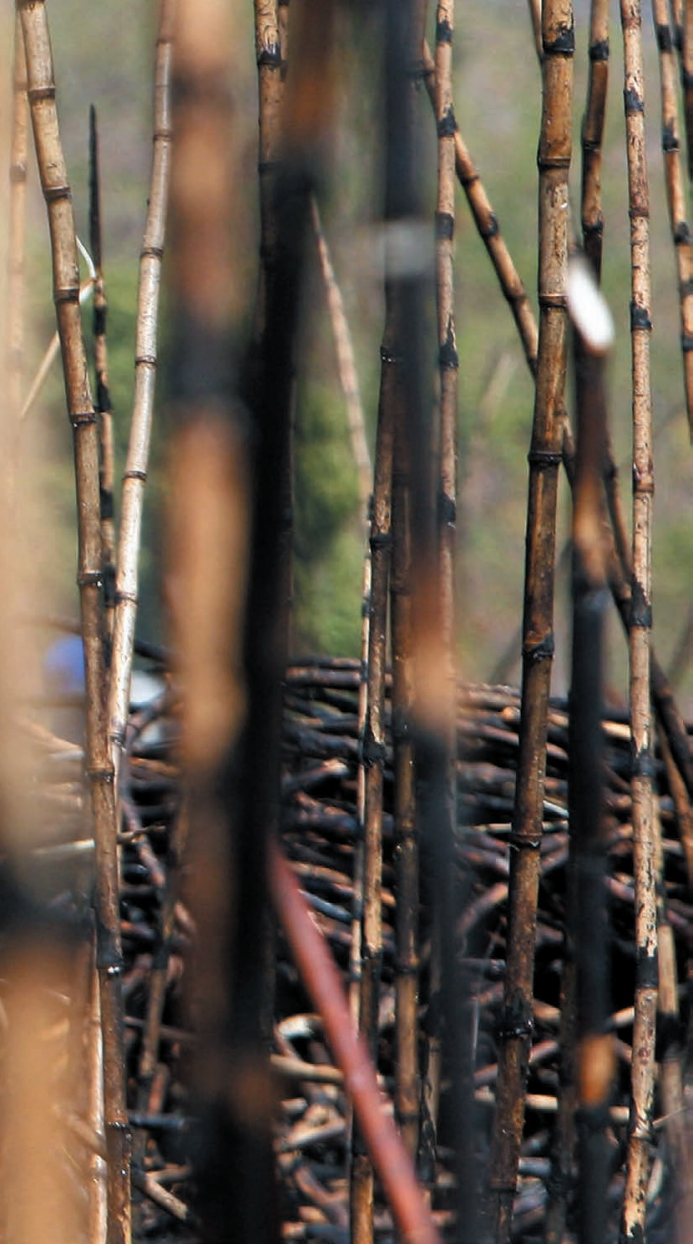

For example, much of the uncertainty in the relationship between emissions in 2050 and eventual temperature rise stems from the possibility of compensating for modest shortterm emissions reductions with larger efforts, including negative emissions, in later decades.

An awareness of the diversity of options and their risks is important for making smart policies that allow for regular revisions in light of new information and feedback. More ambitious near-term emissions reductions create more flexibility for responses through the century, depending on whether useful and affordable technologies become available and how climate impacts pan out. Less mitigation early on would constrain options later and compound risks ${ }^{7}$. Shortterm actions - such as the commitments for 2025 or 2030 that countries have made towards the Paris Agreement - can be compatible with a range of long-term targets, depending on the ambition of our efforts later in the century.

Assessing whether current policies are consistent with long-term goals depends on many factors that are impossible to predict with confidence ${ }^{8,9}$. And not knowing how people will respond makes such an assessment even harder. So emissions pathways that seem compatible today with a long-term temperature target could lead us to higher or lower - levels of warming, depending on everything from future global climate policies to technology costs to the climate sensitivity of the Earth system. Intensified focus on limiting global warming to $2{ }^{\circ} \mathrm{C}$ or $1.5^{\circ} \mathrm{C}$ decreases the risk of greater warming in the long term, for example a rise exceeding $3{ }^{\circ} \mathrm{C}$, should available technologies turn

"Synergies and trade-offs must be evaluated, including risks arising from mitigation actions - not just inactions." out to be limited or climate sensitivity higher than expected.

Researchers need to assess how different sources of uncertainty affect decisionmaking, especially in worst-case scenarios. What should we do if temperatures start to rise more rapidly or the impacts are more dangerous than we expect? How can we detect such departures and how should we alter course? Climate policies might prove to be harmful and need revising; technology costs might not fall; carbon capture and sequestration might not work.

Inform holistic solutions. A fuller evaluation of risks and options is needed that includes those created by climatechange responses for other policy goals. For example, the assessment of climatechange risks at $1.5^{\circ} \mathrm{C}$ in the IPCC's 2014 Synthesis Report foresaw impacts on coral reefs, Arctic sea ice, water availability, food production and sea-level rise. But the bigger picture should also include issues related to climate mitigation, such as economic duress, land- and water-use trade-offs and calls for high-risk geoengineering methods.

The impacts of climate changes and climate policies will interact if, for instance, a slower reduction in poverty owing to higher energy costs increases vulnerability. Synergies and trade-offs must be evaluated, including risks arising from mitigation actions - not just inactions. Social and climate scientists must investigate the political and socio-economic impacts of climate policies (short- as well as long-term), the distribution of those who benefit and those who are adversely affected, and the influences of powerful interest groups.

It is important to explore how climate responses can advance the Sustainable Development Goals and especially poverty reduction ${ }^{10}$. For instance, improving access to clean energy and decreasing the economic impacts of extreme weather events can accelerate development progress while protecting poorer nations against climate change. Climate action and protection will never be the sole priorities for decision-makers, but they will be integral to the full policy landscape. Research and assessment can create a powerful foundation for these interactions, and empower decisions in the years ahead.

Stéphane Hallegatte is senior economist in the Climate Change Policy Team at The World Bank, Washington DC, USA. Katharine J. Mach is a senior research associate in the Department of Global Ecology, Carnegie Institution for Science, Stanford, California, USA. e-mail:shallegatte@worldbank.org

1. Pachauri, R. K. et al. Climate Change 2014: Synthesis Report. Contribution of Working Groups I, II and III to the Fifth Assessment Report of the Intergovernmental Panel on Climate Change (IPCC, 2014).

2. O'Neill, B. C. et al. Clim. Change 122, 387-400 (2014).

3. Clark, P. U. et al. Nature Clim. Change 6, 360-369 (2016).

4. Steinacher, M., Joos, F. \& Stocker, T. F. Nature 499, 197-201 (2013).

5. Rogelj, J. et al. Proc. Natl Acad. Sci. USA 111 , 16325-16330 (2014).

6. Otto, F. E. L., Frame, D. J., Otto, A. \& Allen, M. R. Nature Clim. Change 5, 917-920 (2015).

7. Edenhofer, O. et al. (eds.) Climate Change 2014 Mitigation of Climate Change. Contribution of Working Group III to the Fifth Assessment Report of the Intergovernmental Panel on Climate Change (Cambridge Univ. Press, 2014).

8. Kriegler, E. et al. Technol. Forecast. Soc. Change 90, 1-7 (2015).

9. van Vuuren, D. P. \& Riahi, K. Clim. Change 104, 793-801 (2010).

10. Hallegatte, S. et al. Shock Waves: Managing the Impacts of Climate Change on Poverty (World Bank, 2016).

A list of co-signatories accompanies this article online at go.nature.com/28jfsrq. choices - such as the multiple pathways to achieve a climate goal - can offer flexibility ${ }^{6}$. 